\title{
Writing centre consultants as critical friends
}

\author{
Janine Esmé Carlse \\ Education Policy Studies, Stellenbosch University, South Africa \\ E-mail: jecarlse@gmail.com
}

\begin{abstract}
"Critical friend" is a term widely used in professional development, teacher education, and evaluation contexts. It is defined by Costa and Kallick (1993) as a trusted person who asks the researcher provocative questions, provides an alternate point of view when needed, and critiques the researcher's work as a friend rather than an antagonist. This theoretical paper aims to initiate a dialogue on how elaborating on the role of the writing consultant as a critical friend could open up university writing centres as spaces of exploration and empowerment for student writers, aiding them in nurturing their academic thinking and voice. The work of the writing consultant, primarily as a critical friend, would be to exercise active listening and pose questions while offering advice and reassurance on the student writer's abilities, promoting trust while helping the student writer to develop the tools to reason, and therefore the freedom and confidence to articulate their arguments. I investigate how framing university writing centres as spaces for facilitating trusting dialogues with a critical friend can encourage student writers to think differently about their tasks, assisting them in overcoming hurdles to find their academic voices in order to succeed at university. By embracing the role of critical friends, writing consultants as advocates for the success of student writers' work provide unusual opportunities to establish supportive relationships that take into account the individual student writer's academic journey, promoting self-reflection rather than simply directing student writers through the task at hand. Additionally, this engagement as a critical friend has the potential to change perceptions of the nature of the support provided by writing centres, their value, and purpose.
\end{abstract}

Keywords: critical friends, writing centres, student writers, writing consultants

\section{Introduction}

Academic writing is a daunting task for many, even more so for students who are embarking on their academic journeys at university. In addition to the social (and economic) adjustments to campus life, identity negotiations, and the pressures of time management, adapting to the academic language of teaching, learning, and writing often presents hurdles to success during a student's freshman years (and beyond). At many universities, writing centres have been tasked with providing support to assist in bridging this gap between academic expectations and the capabilities of student writers when they enter tertiary education. 
Writing centres take on various forms and identities within the institutional contexts of which they form a part. According to Grimm (2009), there are many "unspoken assumptions" that frame and guide writing centre practices. These assumptions about the student writers who make use of the centre, the ways that they learn, and their grasp of academic language inform the pedagogies adopted by writing centres, often with little consideration for the positionalities of both the writing centres themselves and the student writers they are meant to serve (Grimm 2009: 12). In South Africa in particular, our history of a stratified higher education institutional landscape (and society more broadly) has generated specific challenges unique to our post-apartheid context. Therefore, as the positionalities of our higher education institutions, and the students attending them, become more differentiated, and are ultimately informed by the contexts within which they find themselves operating, new approaches to academic support are encouraged.

It can therefore be argued that, although the approaches and pedagogies that informed and framed writing centre engagements were novel and innovative when the work of writing centres was first conceptualised (North 1984, Brooks 1991), they now need to be revisited as they have become somewhat dogmatic. The critical friend approach is one that has been adopted primarily within teacher professional development and assessment practices as a form of structured peer support, and highlights the importance of a dialogical approach to feedback (or feed-forward) that is based on trust and dialogue. Drawing from my experience as a writing centre consultant at Stellenbosch University, I propose that reframing the one-on-one writing consultation as a critical friendship engagement, and particularly the writing centre consultants (or peer tutors) as critical friends, has much to offer to the way that these engagements benefit the student writers whom they serve, and to the way that the writing centre itself is perceived. This article therefore aims to open up a discussion about the possible merits of framing writing centre consultants as critical friends, both in the way that we approach our engagement with student writers, and the writing tasks that they require assistance with.

My hypothesis is that when student writers engage with consultants as critical friends, this engagement opens up a space for honesty, self-reflection, exploration, and empowerment, in turn aiding student writers in nurturing their academic thinking and writing. First, I will briefly elaborate on the unspoken assumptions informing current writing centre pedagogies and services. Second, I will unpack the issue of the usefulness of re-envisioning the one-on-one writing consultant and student writer engagement. Third, the adoption of the concept of a 'critical friend' will be contextualised, and its key elements described, before showing how writing centres are spaces conducive to critical friendship. This paper will therefore show how reimagining engagements between writing consultants and student writers as critical friendships, promoting student success and facilitating self-reflection, could constructively inform writing centre pedagogy and praxis as well as perceptions of the role of writing centres.

\section{2. “Unspoken assumptions" informing writing centre practice}

In a writing centre, the prospective engagements of consultants and student writers entail a process of negotiation, where a number of preconceived assumptions among the writing consultants (as perhaps influenced by their training or expertise) and the student writers (often informed by their positionality, subject knowledge, and perceptions of the role of the writing centre) influence the engagement even before it begins in practice. Furthermore, established writing centre scholarship and pedagogies passed on through consultant training have been 
informed by many "unspoken assumptions" about students, language, literacy, and learning (Grimm 2009).

To a large extent, the scholarship on writing centres from the 1980s onward promoted a noninterventionist ideology "cautioning tutors about imposing their own ideas on a student's text, talking too much, making changes to the student's language, and, generally, having too much influence on the conference" (Clark 2001: 33). Over time, these guidelines for support adopted by writing centre practitioners came to be accepted as a writing centre "bible" or dogma (Clark 2001: 34), making re-envisioning alternatives for writing centre pedagogy and praxis outside of these frames of reference a challenge for practitioners. However, in recent years, writing centre scholarship has shown a shift away from the seminal ideas of Stephen North $(1984,1994)$ and Jeff Brooks (1991), both of whom advocated for this non-interventionist ideology, toward approaches to pedagogy that (while not imposing ideas on the text) acknowledge and take into account the positionalities not just of the student writers whom the writing centres serve, but of the writing centres themselves. The ideals of non-directive pedagogy, aimed at improving the writer not the writing, and a focus on "higher-order concerns" during the consultation engagement, are now being questioned, especially in contexts that do not assume a homogenous (i.e. white, English-speaking, middle-class) student body.

Drawing on her personal experience of working in various writing centres, Grimm (2009) reflects on how the blind adoption of what was considered writing centre "best practice" in many instances led to the "persistent markers of racial and class identity, neighbourhoods, cultures, and languages other than English" being diminished to the status of lower-order concerns (Grimm 2009: 13). Therefore, as writing centres become more conscious of their own positionality within the institutions they support, and begin to question the autonomous model of literacy where "the literacy of the dominant class is believed unproblematically to be the only true literacy" (Grimm 2009: 14), there are now tentative shifts toward more writer-centred approaches that may challenge ingrained understandings of what constitutes writing centre best practice.

For example, a study at the University of Southern California suggests that writing consultants and student writers differ in their perceptions about "a number of elements associated with directiveness" during writing consultations (Clark 2001: 37). If we further unpack the notion of 'directiveness' as a matter of perception (how much influence the consultant is exercising over the student's writing), then it becomes apparent that traditional writing centre pedagogy that favours a non-directive approach from the consultant loses some of its merit. For example, in the study, "students who saw themselves as poor writers tended to attribute a more significant role to the consultants", therefore viewing them as more directive, and "all groups of students seemed satisfied with the consultants' degree of directiveness" irrespective of the perceived degree of directiveness that they received (Clark 2001: 45, emphasis in original). So what could this be alluding to? When critiquing the perceived orthodoxy characterising writing centre pedagogy, Clark suggests that an alternative could lie in "individual attention and the opportunity to discuss a paper in terms of topic and process that contribute most significantly to student satisfaction and that the notion of a 'best' way to conduct a writing center conference, like the 'best' way to do anything involving human interaction, cannot be determined in any absolute sense" (Clark 2001: 46).

Within the broader institutional context, assumptions about the work of writing centres as primarily service-orientated, providing academic support services to higher education 
institutions, also present a challenge to possible re-envisionings of writing centres' practice. It is not new for student writers to harbour certain assumptions as well. Ryan (2002: ix) notes that student writers often visit the writing centre motivated by the need for a good grade, and are thus tempted to take the advice that the consultants offer at face value or as a quick fix to improve their assignment. Because of these assumptions, it becomes somewhat convenient to frame writing centre practitioners' interactions with student writers as transactional, and in turn (often unintentionally) informing our pedagogical practices. There is thus a danger in framing our interactions with student writers as primarily transactional, or as a means to an end, whether that end is to produce good writers or good writing, as it can be argued that in such an interaction the human element is sometimes lost.

\section{Re-envisioning the writing consultant and student writer engagement}

As discussed above, there are many unspoken assumptions that have informed and continue to inform writing centre pedagogy and praxis. If, as noted by Ryan (2002: ix), consultants are to "help writers sort through their ideas, clarify their thoughts, and then communicate them effectively to an audience," then serious consideration needs to be given to the way that writing centres and practitioners can adapt our practices to better suit the diverse groups that we support. This can be seen as a departure from the "one size fits all" approach to academic writing support advocated for in earlier years by practitioners such as North $(1984,1994)$ and Brooks $(1991)$. One widely adopted practice within writing centres is that of one-on-one writing consultant and student writer engagement, and this is where I locate my contribution to this discussion on reenvisioning writing centre pedagogy and praxis.

The role of writing centres in the sphere of academic literacy support, although difficult to quantify, cannot be downplayed. Grimm's article on new conceptual frameworks for writing centres asserts that literacy learning in particular is "recognised as a profoundly social and transformative undertaking in which learners shuttle among discourses" (2009: 15). Therefore, if writing centres are serious about flexible engagements and academic literacy support that facilitates this "shuttling" for student writers from various social, linguistic, racial, and cultural backgrounds, then a shift is needed in the way we frame our engagements with the student writers we serve. A shift of focus from "an academic skills/writing process version of literacy to a consideration of epistemologies, power relations, identities, and ideologies that circulate in different discourses" (Grimm 2009: 15) is therefore encouraged.

It can then be argued that when we begin to think about re-envisioning the writing consultant and student writer engagement, special attention should be given to what Trimbur (2011:2) acknowledges as the unique positionality of writing consultants in their "capacity to foster conversations with students about the stresses and strains of academic literacy". Whether or not this actually happens in the writing centre engagement may depend on the particular consultation, but this could also be fostered if the engagement is one that promotes trust and dialogue. In addition, within the broader institutional culture, writing consultations are unusual engagements that diverge from traditional classroom-based dynamics that cannot offer students an opportunity for this level of interaction.

Therefore, in agreement with Archer and Richards (2011), my view is that writing centres and their consultants should not underestimate the affective side of the role that they play within the broader institutional environment, which can be perceived as harsh and alienating for many 
students. By working with student writers individually, writing centres could offer a welcome departure from "most other formal ways of teaching" (Archer and Richards 2011: 9), and embody a great potential for re-envisioning the writing consultant and student writer engagement. In this light, humanising writing centre pedagogies and engagements characterised by compassion should be promoted, rather than implementing generic approaches that could further entrench the alienation that student writers may feel (Archer and Richards 2011: 12). I propose that regarding writing consultants as critical friends would be a conceptual step toward realising this goal.

\section{What is a critical friend?}

The critical friend approach to peer support has emerged in the literature largely within the context of teacher education, professional development, and evaluation (Costa and Kallick 1993; Swaffield 2005, 2007, 2008), with recent literature also profiling the usefulness of the approach in adult learning and doctoral study support (Smith, Wood, Lewis and Burgess 2016; Storey and Wang 2017). Costa and Kallick (1993: 49) provide the most widely cited definition of "critical friend" as a "trusted person who will ask provocative questions and offer helpful critiques". More specifically:

A critical friend takes the time to fully understand the context of the work presented and the outcomes that the person or group is working toward. The friend is an advocate for the success of the work.

Costa and Kallick (1993: 50)

What is particularly interesting about the concept of having or being a 'critical friend' is the inherent tension between the critical friend's role as being at once a "challenging critic and a trusting friend" (Storey and Wang 2017: 107). From an adult-learning perspective, Storey and Wang (2017: 112) elaborate on Costa and Kallick's seminal thoughts on the value of engaging with a critical friend: they postulate that by prioritising open interactions, critical friends create opportunities to "make sense of complex ideas and construct their own understanding, as opposed to interactions where they are told what to do or how to think". In this light, a critical friend undertakes a commitment to learning and dialogue (Storey and Wang 2017: 113). Also drawing on the work of Costa and Kallick (1993), Swaffield, speaking from a schooling context, postulates that the success of a critical friendship is dependent on three interrelated conditions of trust, engagement, and commitment (dialogue), as well as the critical friend's knowledge or expertise (Swaffield 2007: 205). It has even been proposed that students and researchers should be exposed to the notions of 'criticality' and 'critical friendship' from an early stage in their academic journeys in the form of supportive peer assessment and review (Smith et al. 2016: 246).

When framed within these parameters, the critical friend engagement (critical friendship) can be a rewarding experience. It provides a balance between challenge and support as facilitated through a process of dialogue that is premised on trust in the ability of the critical friend and commitment on behalf of both individuals involved in the engagement. Drawing on the literature, it is at this point that I elaborate on trust and dialogue as integral to the success of the critical friend engagement. 


\subsection{Trust as the foundation}

The importance of trust within the critical friend engagement is mentioned across the literature (Costa and Kallick 1993; Swaffield 2005, 2008; Storey and Wang 2017), with Swaffield (2008) going as far as advocating trust as the bedrock of critical friendship. It can be argued that an engagement built on trust mitigates the risks that come with providing a critique; also, "because the concept of critique often carries negative baggage, a critical friendship requires trust and a formal process" (Costa and Kallick 1993: 50). According to Costa and Kallick (1993: 50), critical friendships must begin through building trust. For this to happen, the writer or student needs to feel that:

- The critical friend is not there to evaluate/judge;

- The critical friend will listen well to fully understand (exercise active listening);

- The critical friend will "offer value judgements only upon request" from the student;

- The critical friend will "be an advocate for the success of the work".

Costa and Kallick (1993: 50)

Elaborating on these early assertions by Costa and Kallick (1993), Storey and Wang (2017: 110) observe that collaborative groups develop trust once they embark on a journey to understand "each other's work contexts, problems and challenges, and presented data". In this way, they open avenues toward discerning, supportive, and honest feedback and critique. In this light, trust becomes essential to favourable learning conditions where individuals feel safe to "take risks, cope with failure and respond positively to challenges" (Swaffield 2008: 332). It can also be argued that an imbalance of power, even if it is only a perceived imbalance, can impede trust. Trust within the critical friend engagement is therefore linked to a sense of security, and this security could allow the individuals involved in the critical friend engagement to be more open to critique or expressing their vulnerability. This "secure vulnerability" (two words in tension, much like "critical friendship" itself) encourages the asking of questions and signalling of uncertainty. For this exchange to be successful, it therefore requires a mutual trust in the expertise and intentions of the critical friend, and in the abilities and commitment of his/her peer.

\subsection{Dialogue at the heart}

If we understand writing as a process of meaning making, then dialogue is an important aspect within this process. For this reason, dialogue with a critical friend provides a constructive framework within which to facilitate this process of meaning making within an engagement based on trust. The term "dialogue" is defined by Swaffield (2008: 328) as "a very particular form of conversation involving the exchange of ideas and the search for shared meaning and common understanding, quite different in form and purpose from casual chat or combative debate". Dialogue is thus not possible without some form of mutual trust between the individuals involved in the engagement. It can therefore be argued that dialogue is at the heart of critical friendship, but a condition for effective dialogue is a mutual sense of trust.

Swaffield (2008: 328-329) affirms the significance of dialogue within a critical friendship by providing a short literature review of the pedagogical merits of dialogue based on trust and 
honesty. Swaffield's review shows that constructivist and social approaches to learning emphasise dialogue, foster collaborative learning and new ideas, and enhance reflection (Carnell and Lodge 2002; Alexander 2004; Pollard 2005; Watkins 2005, cited in Swaffield 2008). Facilitated reflection can be powerful on various levels. Through probing dialogue and reflection, a critical friend can lead the student or researcher to new insights in a supportive and cooperative way (Kember, Ha, Lam, Lee, Ng, Yan and Yum 1997; Williams and Todd 2016). The new insights uncovered in turn contribute to the nurturing of the student's or researcher's academic voice.

At this point, I direct the discussion toward an unpacking of how writing centre consultants can contribute to a positive re-envisioning of writing centre pedagogy and praxis through fulfilling the role of critical friends during their engagements with student writers.

\section{Writing centres as spaces conducive to critical friendship}

In a study conducted on educational professionals from various backgrounds studying towards a Doctor of Education degree at a British university, an intervention consisting of a "critical writing weekend" was implemented that "engaged students in peer assessment processes founded on the principles of critical friendship" (Smith et al. 2016: 245). Through this study, the researchers came to the conclusion that:

Notions of criticality and critical friendship need to be explored and discussed with students from an early stage [...] The difference between camaraderie and critical friendship needs to be clearly articulated and exemplified, as a shared understanding of this cannot be assumed. This research has indicated that criticality can be reconceptualised as caring work and as a part of the collective responsibility of a community of researchers.

Smith et al. (2016: 246)

This assertion alludes to the importance of dialogue and working outside of silos in structured yet fluid ways, where students are enabled to experience critical friendship to the benefit of their own working relationships as researchers (Smith et al. 2016: 246). Through these types of engagements, the importance of friendship as the basis for constructive critique, that is buttressed by caring, then forms the foundation or collective understanding of supportive criticality between peers. Drawing on the findings of Smith et al.'s (2016) study, it can be argued that critical friendship has the potential to build a renewed foundational understanding of academic writing support that can "significantly enhance students' learning and experience of postgraduate study, building researcher expertise and resilience" (Smith et al. 2016: 248).

When applying this to the context of writing centres, the notions of 'criticality' and 'critical friendship' can be introduced to student writers at an early stage of their academic journeys, as the writing centre serves students on all levels and at various stages of the writing process. I therefore argue that writing centres are spaces conducive to this critical friendship engagement, both physically and in perception, in which student writers are guided in taking ownership of their academic writing in an empowering way. Archer and Richards (2011:6) assert that, as liminal spaces somewhat removed from the day-to-day workings of the university, writing centres are "uniquely empowering spaces which can contribute to the quest for social equality in ways that few other university structures can". Because writing consultants often have to 
"negotiate and mediate the uneven power relations that may exist" (Archer and Richards 2011: 11-12), in a move toward a more egalitarian engagement in co-constructing knowledge with student writers, reframing the roles of writing consultants or peer tutors as critical friends could offer certain benefits. I therefore advocate for the value that repositioning writing consultants as critical friends could offer toward a re-envisioning of writing centres in terms of perceptions and practice on university campuses.

\subsection{Envisioning writing consultants as critical friends}

Whatever the specific context, the critical friend is generally portrayed as a detached outsider who assists through questioning, reflecting back and providing another viewpoint. The critical friend prompts the other person towards honest reflection and re-appraisal, a seeing anew that may be challenging and uncomfortable, yet enhancing. The relationship is neither cosy nor collusive, but rather one that cultivates constructive critique.

Swaffield (2007: 205-206)

As touched on earlier in this article, the usefulness of the critical friend approach has been advocated for in various settings such as the classroom, in staff development, and between educational administrators (Costa and Kallick 1993: 50-51). I extend this usefulness to the oneon-one writing consultations between writing consultants and student writers. As "detached outsiders" providing input on academic writing in a neutral yet structured environment, writing consultants are well placed to take up the role of critical friends. On a practical level, Williams and Todd (2016: 2165) assert that successful critical friend engagement depends on both parties showing a commitment to the task at hand, setting aside a specific time and place, and discussing "the protocols or preconditions that will guide the intense work to be done". The writing centre environment therefore already ticks these boxes as it provides a neutral space for engagement, where the student writers exercise agency in deciding to visit the writing centre, bringing their subject knowledge and ideas to the engagement, while the writing consultants bring their writing expertise as they have been trained and have gained experience in academic literacy support.

Costa and Kallick (1993) provide an example of what a critical friend engagement could look like in practice. They limit the engagement to about twenty minutes, and outline clear steps that begin with the student (writer) first describing the task and requesting feedback, the critical friend (consultant) then asking questions to understand the task at hand, and at this point the student (writer) sets the desired outcomes for the engagement. This is not a major departure from the conventions that writing consultants are generally trained in, so these initial steps will be familiar to writing centre practitioners. In indicating the steps that guide the second part of the engagement, Costa and Kallick (1993) go into some depth about the ways that the critical friend can provide significant feedback, and raise questions and critiques that prompt the student (writer) to see the task from various perspectives, informing a dialogue and ultimately leading to both parties reflecting on and noting key take-aways from the session. It can be argued that the second part of the engagement therefore emphasises the role of the critical friend as at once an advocate for the success of the work and a facilitator of self-reflection for the student (writer).

Specifically in the context of the writing centre, when elaborating on what she calls "one-onone multimodal pedagogy", Archer (2017: 5) notes the importance of a student-centred environment where students feel comfortable in exploring and experimenting with writing, and 
receiving "assistance from a critical but supportive audience in one-on-one consultations". Archer therefore alludes to what could be considered a critical friend engagement, where the writing consultant "guides students' thoughts and writing processes by questioning and clarifying, so that students learn to convey their meaning more effectively, and feel confident to be able to enter the academic debate" (Archer 2017: 5). This engagement can therefore facilitate "metacognitive activity" (Archer 2017: 6) on the part of the student writers which could assist them in becoming more conscious of their writing process and academic voice.

\subsection{The critical friend as an advocate for the success of the work}

As previously mentioned, student writers come to writing consultations with their own assumptions and expectations. These assumptions are often informed by perceived power relations between the writing consultants and the student writers, where writing consultants are perceived to be the givers and student writers the receivers of knowledge. Hence this tends to mimic normalised pedagogical approaches within the university environment. It can be argued, however, that if the student writers are expecting to speak to critical friends, they may feel more at ease about sharing their experiences of writing. As it is broadly understood that friendship is based on a caring relationship, expecting to engage with a critical friend could then encourage student writers to come into the encounter more psychologically prepared to openly engage outside of the normalised campus-bound power dynamics.

From the writing centre's perspective, Archer and Richards (2011: 8) acknowledge that effective "teaching of writing involves a dialogue between the discourses of academia and those of students, offering those from disadvantaged backgrounds an empowering and critical experience, not just bridges to established norms". If writing consultants are advocates for the success of the work, then our approaches to academic support should employ strategies to enable these empowering critical dialogues. As Swaffield (2008: 332) asserts, unless "people feel secure, they will not try approaches new to them since these are by definition untested and unproved, and a fundamental sense of security is essential if people are to embrace novelty willingly, and thus to learn". As noted earlier, mutual trust plays an important role in establishing this sense of security within the critical friend engagement.

Archer (2017: 6) proposes that writing centres should "embrace the complex relationship between the spoken and the written, and how the written is understood by a reader", and, in doing so, "offer students the opportunity to articulate problems and to explain what they are doing". As an advocate for the success of the work, the consultant who actively listens to the student writer's concerns becomes an integral part of this process, rather than adhering to rigid conceptions of what could be considered directive or non-directive assistance. In addition to blurring the lines between directive and non-directive engagement, framing the writing consultant and student writer engagement within the parameters of critical friendship foregrounds the writing consultant's role as an active listener. Offering constructive critique as part of the process of teaching writing can therefore be encouraged through a more organic engagement between writing consultants and student writers, ultimately offering a more holistic approach to advocating for the success of student writers' works. 


\subsection{The critical friend as a facilitator of self-reflection}

Talk is one of the multimodal approaches that Archer describes as a means to improve student writing within the one-on-one consultation. This approach places the emphasis on discussion and argument. According to Archer, the "consultant's task is to help students to acquire a vocabulary or 'metalanguage' that allows them to draw back from what they have written, to talk about their writing, and to develop self-critical practices in order to appraise their work as they progress" (Archer 2017: 6). In my personal practice as a writing consultant, I often ask student writers what their broader study plans are, or what their course stream is, or what made them decide to pursue the topic that they have selected. In this way, as a consultant, I can learn more about the student's motives, while the student writer has an opportunity to reflect on the way that the task at hand fits into the broader goals of their academic journey. For instance, if a student writer is doing Social Work, and is struggling to address a question related to the use of a case study and theory, I would propose that they see themselves in the shoes of a social worker, and think about how they would approach the problem.

As important as it is to deal with the task at hand, a writing consultant in the role of a critical friend can facilitate self-reflection by giving "students the opportunity to articulate problems and to explain what they are doing" (Archer 2017: 6), thereby empowering the student writer to take ownership of their work through the process of self-reflection. Costa and Kallick (1993: 51) assert that the critical friend engagement has the potential to "build greater capacity for selfevaluation as well as open-mindedness to the constructive thinking of others". Much like dialogue is predicated on trust, self-reflection can be promoted and enhanced through dialogue. In this light, in addition to enhancing critical thinking, critical friend engagements have the potential to evoke self-reflection (Storey and Wang 2017: 112-113). A critical friend engagement can therefore act as a springboard for deeper engagements, not just with the project at hand, but also with the student writer's positionality in relation to the project.

It can be argued that critical friendship advances humanising rather than transactional engagements. The conceptualisation of writing consultants as critical friends can therefore have an effect on student writers' perceptions of writing centres, and the types of engagements that they can expect when visiting the writing centres on their campuses. In addition to being easily adapted to the writing centre context, critical friendship can become a viable approach to engaging with student writers and their research in a way that advocates a reflective approach to self-development, peer-support, and academic empowerment. By familiarising student writers with this kind of approach to peer support and empowerment, students (and researchers more broadly) can in turn themselves be motivated to engage in this form of collaborative learning with their peers.

\section{Concluding remarks}

This article has opened up a discussion on the possible merits of conceptualising writing centres as spaces for critical friendship, where one-on-one writing consultations become engagements premised on trust and dialogue, ultimately facilitating self-reflection by student writers and a more organic way of approaching academic writing support. If we as writing centre practitioners reflect critically on the "very nature of dialogic learning and the conditions that support and enhance it" (Swaffield 2008: 334), then we can possibly come to see the merit of a writer-centred approach rather than a procedural approach to our work. I think that a viable step 
towards this critical reflection would be considering what it means for writing consultants to position themselves as critical friends within our centres.

By opening up a discussion on the potential of adopting the critical friend approach to engagements between writing consultants and student writers within the context of the writing centre, I have attempted to show how the work of the writing centre could be further enhanced by approaches to providing student support that are cognisant of the human aspect of our interactions with student writers. Moving toward approaches that favour more organic and humanising engagements with student writers therefore has much to offer in the re-envisioning of writing centre pedagogy and practice. Ideally, writing centres should offer safe yet critical spaces for student writers, encouraging participation and self-reflection, and allowing students to talk about their concerns as well as aspirations, rather than just providing directive support. Writing centres should therefore provide a space where student writers can feel comfortable about shaping and embracing their academic voices.

This article has argued that, if as writing centre practitioners we are thoughtful about our approaches to student writer support, acknowledging each student writer's positionality and potential, then the expectations that we bring into our engagements with student writers will be framed within a discourse that seeks to facilitate the student writer's becoming. This is therefore a departure from what has become writing centre dogma that emphasises sticking to the "rules of the game" over more organic approaches to academic support. Therefore, the merits of promoting critical friendship within writing centre contexts largely lie in locating peer review or assessment within a structured yet humanising engagement, rooted in trust and dialogue, with the potential to facilitate self-reflection.

I am not contending that a critical friend methodology is the only approach to writing centre engagement with student writers, but I do see potential in the adaptability of this humanising approach to the writing centre context. Critical friendship, in essence, has the potential to facilitate open engagement and more realistic expectations, while flattening the power dynamics between consultant and student writer. By engaging with writers as potential friends, our engagements also have the potential to become more considered as we invest personally in their success as friends.

\section{References}

Archer, A. 2017. Using multimodal pedagogies in writing centres to improve student writing. Stellenbosch Papers in Linguistics Plus 53: 1-12. https://doi.org/10.5842/53-0-730

Archer, A. and R. Richards. 2011. Writing Centres as alternate pedagogical spaces. In A. Archer and R. Richards (eds.) Changing spaces: Writing centres and access to higher education. Stellenbosch: Sun Press. pp. 5-15.

Brooks, J. 1991. Minimalist tutoring: Making the student do all the work. Writing Lab Newsletter 19(2): 1-4.

Clark, I. 2001. Perspectives on the directive/non-directive continuum in the writing center. The Writing Center Journal 22(1): 33-58. 
Costa, A. and B. Kallick. 1993. Through the lens of a critical friend. Educational Leadership 51(2): 49-51.

Grimm, N. 2009. New conceptual frameworks for writing center work. The Writing Center Journal 29(2): 11-27.

Kember, D., T-S. Ha, B-H. Lam, A. Lee, S. Ng, L. Yan and J. Yum. 1997. The diverse role of the critical friend in supporting educational action research projects. Educational Action Research 5(3): 463-481. https://doi.org/10.1080/09650799700200036

North, S. 1984. The idea of a writing center. College English 46: 433-446.

North, S. 1994. Revisiting the idea of a writing center. The Writing Center Journal 15(1): 7-19.

Ryan, L. 2002. The Bedford guide for writing tutors. Boston: Bedford/St. Martin's.

Smith, J., P. Wood, G. Lewis and H. Burgess. 2016. Critical friendship as a pedagogical strategy. In V.A. Storey (ed.) International perspectives on designing professional practice doctorates. New York: Palgrave Macmillan. pp. 233-248. https://doi.org/10.1057/97811375 2706614

Storey, V. and V. Wang. 2017. Critical friends protocol andragogy and learning in a graduate classroom. Adult Learning 28(3): 107-114. https://doi.org/10.1177/1045159516674705

Swaffield, S. 2005. No sleeping partners: Relationships between head teachers and critical friends. School Leadership and Management 25(1): 43-57. https://doi.org/10.1080/136324305 $\underline{2000317082}$

Swaffield, S. 2007. Light touch critical friendship. Improving Schools 10(3): 205-219. https://doi.org/10.1177/1365480207077845

Swaffield, S. 2008. Critical friendship, dialogue and learning, in the context of Leadership for Learning. School Leadership and Management 28(4): 323-336. https://doi.org/10.1080/13632 $\underline{430802292191}$

Trimbur, J. 2011. Foreword. In A. Archer and R. Richards (eds.) Changing spaces: Writing centres and access to higher education. Stellenbosch: Sun Press. pp. 1-3.

Williams, J. and R. Todd. 2016. Debriefing the interpretive researcher: Spider sniffing with a critical friend. The Qualitative Report 21(12): 2161-2175. 